\title{
A PRAÇA É NOSSA - ANÁLISE DA INTERVENÇÃO NA ÁREA DO TERMINAL RODOVIÁRIO DE PRESIDENTE PRUDENTE
}

Karin Fernanda Schwambach ${ }^{1}$, Jeanete Carolina Horst Maciel ${ }^{2}$

${ }^{1}$ Msc. Arquitetura e Urbanismo. ${ }^{2}$ Discente do Curso de Arquitetura e Urbanismo da UNOESTE. E-mail: karin.schwambach@yahoo.com.br

\section{RESUMO}

O Terminal Rodoviário Comendador Walter Lemes Soares, importante equipamento urbano de Presidente Prudente, localiza-se próximo a região central da cidade. Atualmente, seu contexto apresenta baixa qualidade ambiental devido uma somatória de fatores, tais como: falta de manutenção da edificação, degradação da rua e de seus elementos, áreas de prostituição, comércio informal, ocorrências de violência urbana, conflito no tráfego de pessoas e veículos. Em 2012, o local passou por reformas no prédio e intervenções em seu entorno imediato, cujas ações tiveram um forte impacto local. Considerando o potencial urbanístico deste equipamento urbano, bem como a importância desta área para a cidade, os alunos fizeram uma intervenção artística para instigar uma reflexão sobre a cidade que queremos. Este artigo tem por objetivo trazer uma analise do projeto executado trazendo questionamentos e fomentando outras possibilidades de atuação nesta área.

Palavras-chave: Terminal Rodoviário Comendador Walter Lemes Soares, Requalificação Urbana, Intervenção Urbana, Urbanismo, Presidente Prudente.

\section{INTRODUÇÃO E OBJETIVO}

O Terminal Rodoviário Comendador Walter Lemes Soares de Presidente Prudente é o principal dessa modalidade do transporte coletivo regional. Este importante equipamento público juntamente com outras atividades de comércio e serviço desenvolvidas nas proximidades apresentam problemas de estacionamento, tráfego local intenso, degradação de infraestrutura urbana e áreas verdes, marginalização e violência urbana. Ano passado (2012) passou por reformas, cujas propostas não solucionaram várias das dificuldades existentes.

Sendo assim, o presente trabalho tem por objetivo questionar e analisar as intervenções urbanas elaboradas na área do Terminal Rodoviário Comendador Walter Lemes Soares de Presidente Prudente com a expansão do estacionamento sob a praça, a inserção de grades na mesma, a diminuição de áreas verdes, envolvendo questões sociais e não solução do problema e o tráfego local. 


\section{METODOLOGIA}

O trabalho foi realizado através de levantamentos históricos, socioeconômicos, de infraestrutura, pesquisas documentais e fotográficas a fim de compreender o objeto de estudo. Realizaram-se entrevistas com usuários de diferentes idades e níveis econômicos, bem como com os principais atores urbanos obtendo percepções a cerca do ambiente que frequentam para trabalhar ou passear.

Buscando a identificação dos elementos que compõem a identidade da cidade, foram aplicadas metodologias de Kevin Lynch (1960) por meio da elaboração de mapas mentais e leitura do bairro.

Além disso, elaborou-se uma proposta de intervenção urbana na Praça dos Pioneiros, chamada "A Praça é Nossa" com cartazes e painéis pintados, trazendo ao espaço público mobiliários feito com materiais de reuso e usufruindo da praça com um piquenique.

\section{RESULTADOS}

Após análise das intervenções no terminal em escala urbana, notou-se a ampliação do estacionamento supriu a necessidade imediata por vagas, mas provocou uma série de consequências indesejáveis. São estas: a obstrução da passagem de pessoas pelo meio da praça, fechamento com grades da Praça dos Pioneiros, aumento de área impermeabilizada de solo, afastamento de dos "olheiros" naturais, diminuição do potencial transformador que um espaço público de qualidade pode oferecer. Até onde se sabe, ainda não foram desenvolvidos projetos para melhorias da infra estrutura local, para o tráfego e conflitos na circulação de pedestres, para melhoria da praça e nem para melhorar de índices de marginalização da área. 


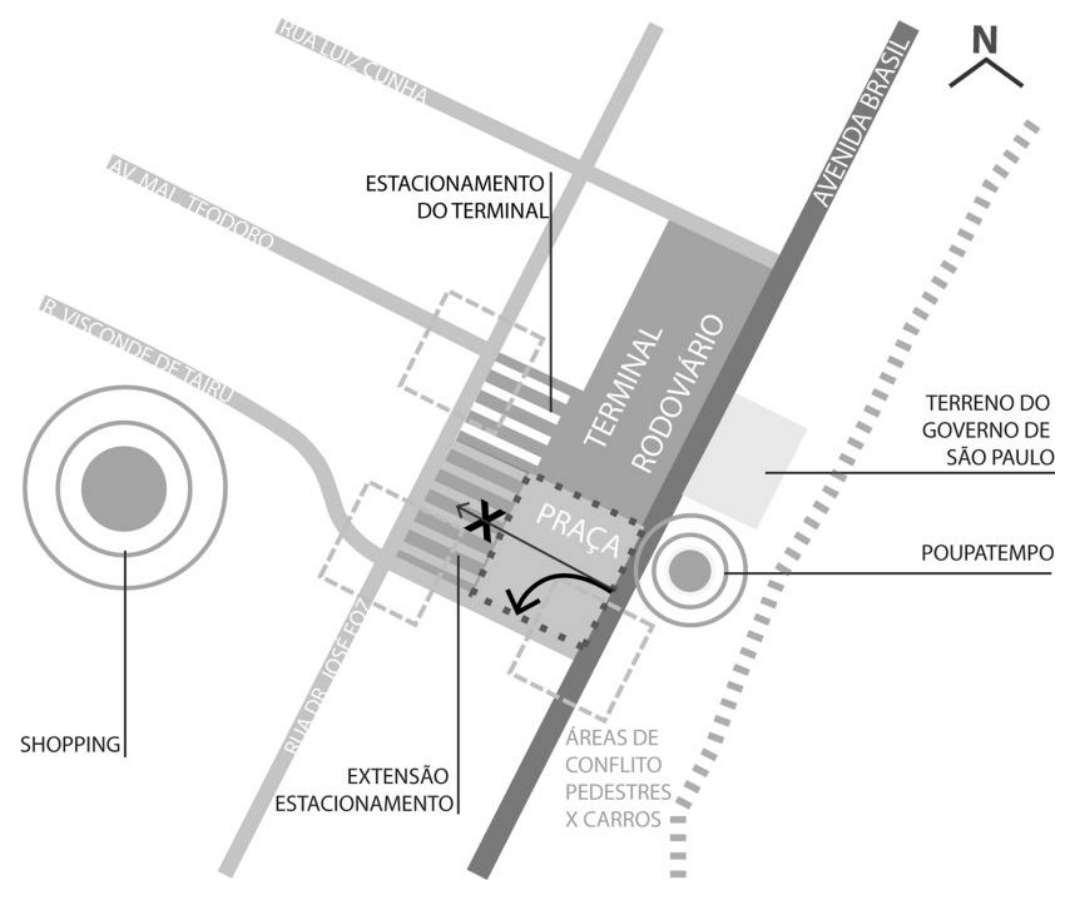

Figura 01. Diagrama da área do terminal

Fonte: Elaborado pelas autoras

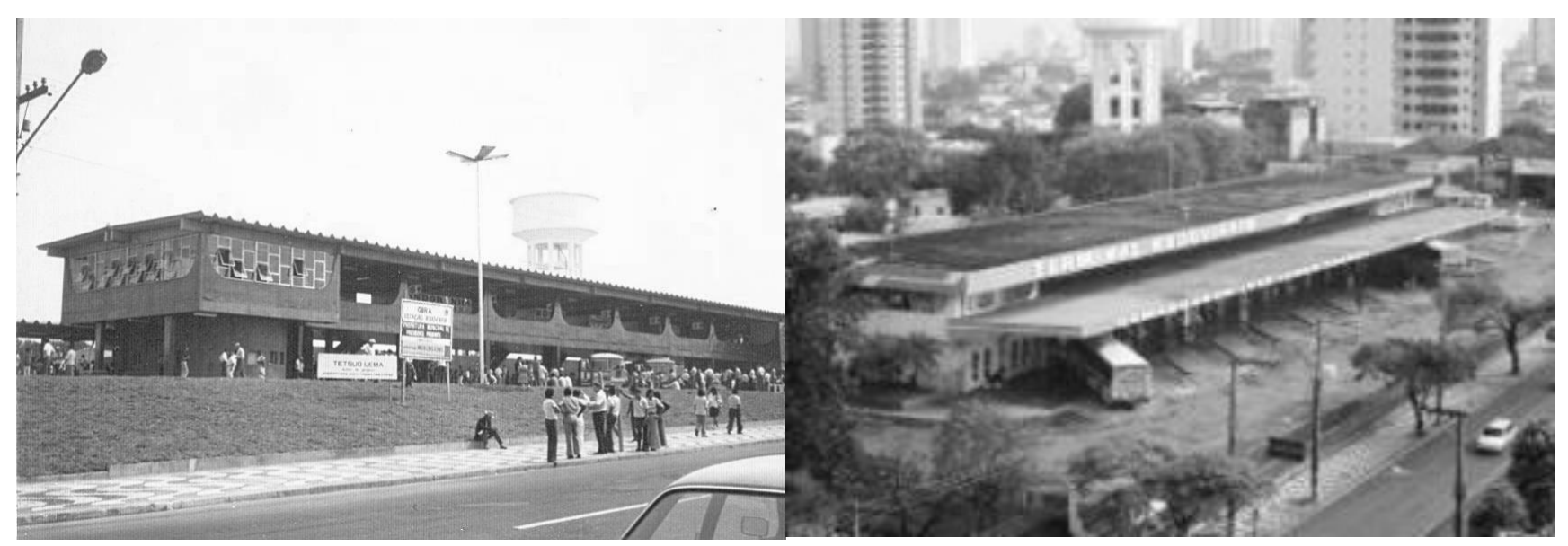

Figura 02. Inauguração do terminal, década de

Figura 03. Terminal rodoviário, década de 1990. 1970.

Fonte: Arquivo Museu Municipal.

Fonte: Arquivo Museu Municipal. 


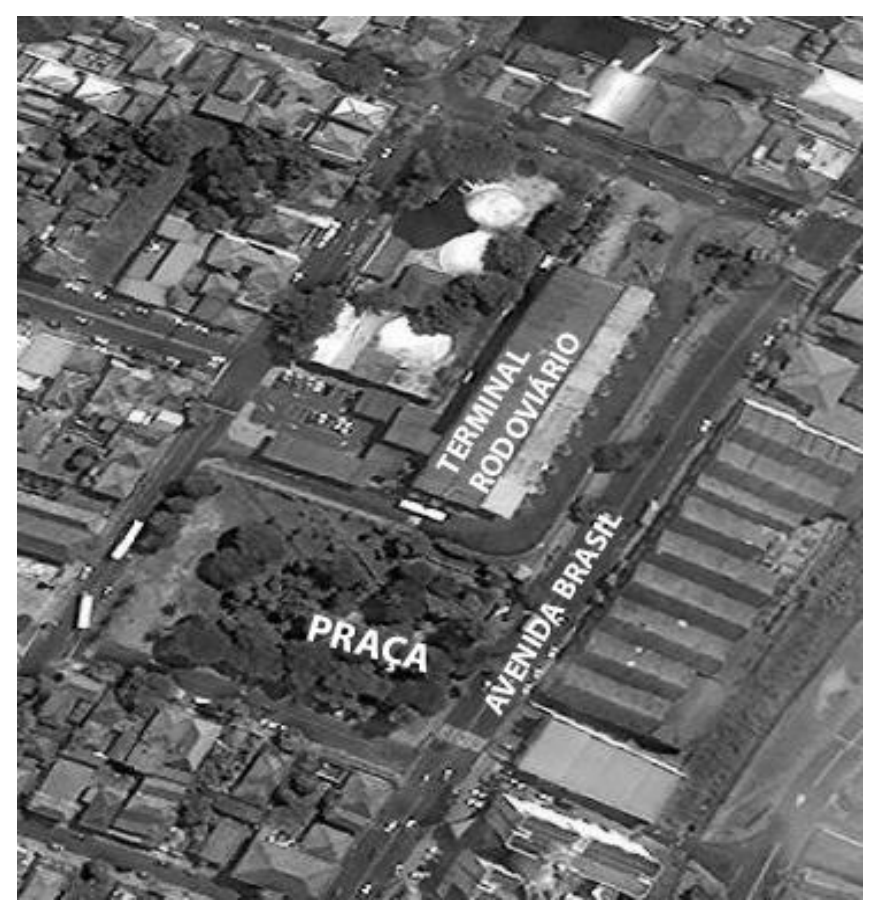

Figura 04. ANTES - Terminal Rodoviário, a praça e terreno com área verde (03/2012) Fonte: Bing Maps.

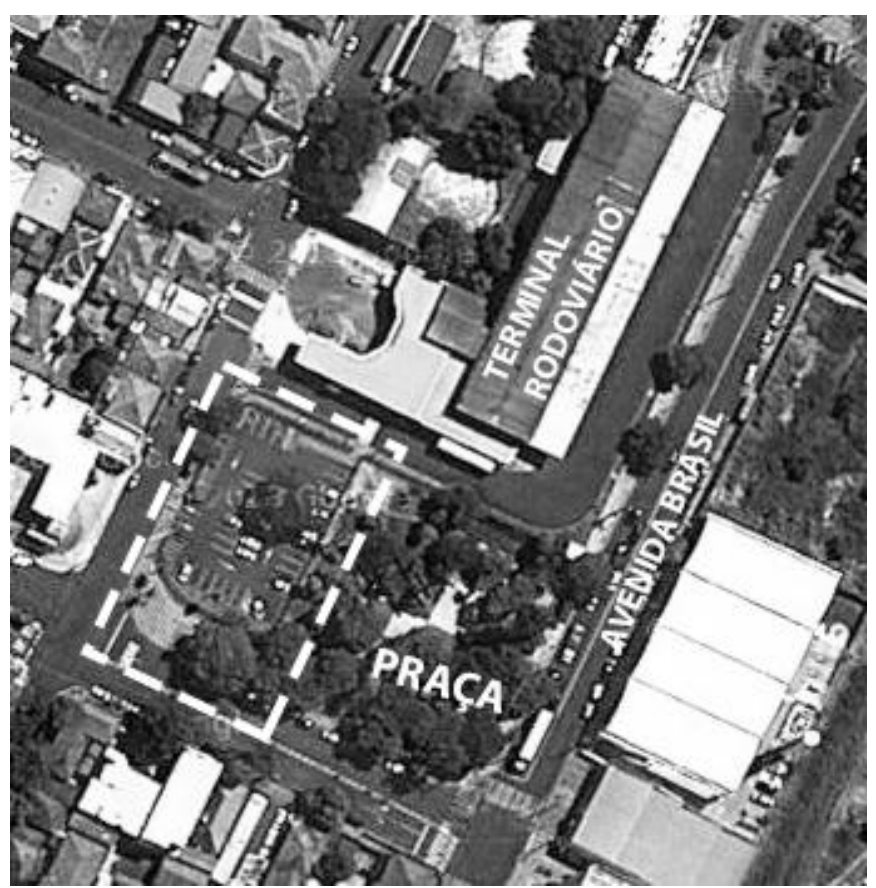

Figura 05. DEPOIS - Terminal Rodoviário, praça e o estacionamento $(10 / 2012)$

Fonte: Google Maps

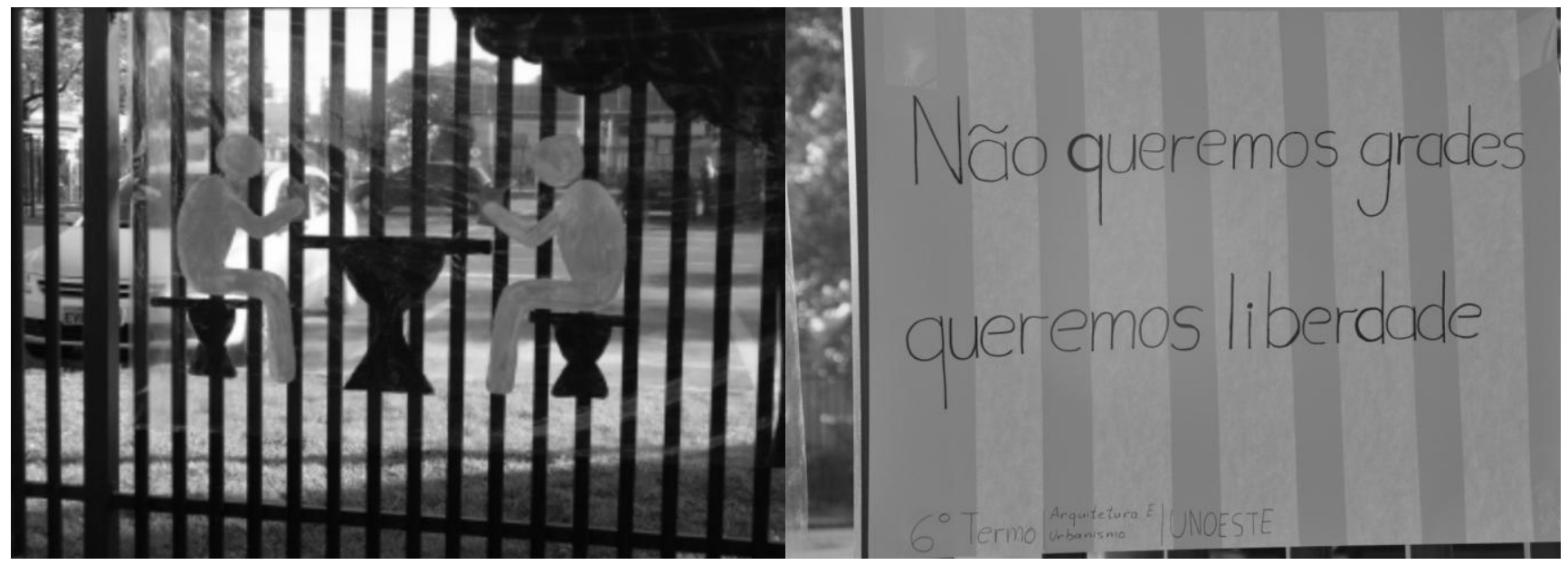

Figura 06. Intervenção "A Praça é Nossa". Foto: SCHWAMBACH (2012)
Figura 07. Intervenção "A Praça é Nossa".

Foto: SCHWAMBACH (2012)

\section{DISCUSSÃO}

A Vila Nova e Vila São Jorge desenvolveram rapidamente, caracterizando-se como a expansão do centro histórico de Presidente Prudente/SP. Consolidou-se ali, um local de residências, comércio, serviços e importantes equipamentos urbanos, como o Hospital Santa Casa de Misericórdia, Fórum e o Terminal Rodoviário Comendador Walter Lemes Soares. Mais recentemente implantaram-se também o Poupa Tempo e o Prudente Parque Shopping. 
O terminal teve a sua inauguração em 1970, na Avenida Brasil, uma das principais avenidas com diversos tipos de comércio. A foto da inauguração do terminal retrata a arquitetura original, e visivelmente é um equipamento permeável, permitindo o livre acesso de pessoas.

Projeto concebido pelo arquiteto Tetsuo Uema, formado pela FAU-USP apresenta uma arquitetura em concreto aparente com composição simétrica, sendo dois blocos sobressaltados nas extremidades vedados em vidros e um grande elemento elevado sob pilotis, com aberturas em " $U$ " (vide figura 2). Na área superior concentram-se os guichês de vendas, e na parte inferior os embarques e desembarques.

Ao andar pela Avenida Brasil, ainda é possível reconhecer várias edificações datadas de 1920, que silenciosas têm suas fachadas escondidas embaixo das marquises publicitárias das atividades comerciais. Como uma das importantes ligações no sentido "norte-sul" na cidade tornou-se um corredor com tráfego intenso.

Ao lado do terminal, está a Praça dos Pioneiros, que como outras da cidade, encontrava-se degradada com falta de manutenção. Ela era usada como local de passagem para pedestres e os usuários de ônibus, que esperam no ponto as conexões regionais. Devido o abandono, a praça geralmente é ocupada por pessoas em situação de rua, ambulantes e é possível observar atividades como comercialização de produtos ilícitos.

Contextualizando a área de estudo, nota-se que a reunião de grandes equipamentos públicos na região gera um fluxo constante de pessoas e veículos. Na Avenida Brasil, logo em frente a praça está implantado o Poupatempo, um importante equipamento urbano que reúne órgãos e empresas prestadoras de serviços de natureza pública do Estado de São Paulo para atendimento ao cidadão. Próximo ali, encontra-se o Prudente Parque Shopping, um grande centro comercial da cidade.

Porém, mesmo o shopping estando tão próximo do terminal rodoviário, é possível perceber uma grande diferença física e social dessas duas localidades.

A Avenida Brasil passou por transformações cuja infraestrutura de suporte não acompanhou a responsabilidade que ela foi assumindo, tornando-se uma via de difícil mobilidade para pedestres, sinalização e calçamento precários, baixa qualidade urbana, com muita poluição sonora e do ar. Identificou-se três áreas de conflitos entre pedestres e veículos (ver Figura 1).

O mesmo aconteceu com o Terminal Rodoviário, a infra estrutura não acompanhou o crescimento da demanda. As intervenções feitas ao longo dos anos modificaram sua implantação em relação ao entorno, fecharam gradis o terminal interrompendo a conexão com a Praça dos 
Pioneiros e a Avenida Brasil, mas não conseguiram proporcionar uma inserção que apresente qualidade urbana para os que ali frequentam.

Em agosto de 2012, quando foi realizado o primeiro levantamento para esta pesquisa, o terminal rodoviário passava por reformas de melhorias físicas, que incluíam ampliar a área de estacionamento, modernização das lanchonetes, banheiros, melhoria dos acessos (escadas, rampa), nova cobertura do ponto de táxi e a cobertura da entrada principal do estacionamento. De todas essas, a intervenção que mais nos chamou atenção foi a ampliação do estacionamento.

O estacionamento foi expandido para o lote lateral, que anos atrás a prefeitura tinha desapropriado para ampliação do terminal rodoviário. Enquanto não houve a ampliação, a área foi "agregada" e estava sendo utilizado como extensão da praça. Impermeabilizou-se uma área equivalente a 50 novas vagas para carro. Além disso, praça também foi cercada, modificando a travessia e interrompendo de vez qualquer com a comunicação com o terminal.

Diante desses fatos surgiram alguns questionamentos como: se este lote prefeitura é para ampliação do terminal rodoviário, porque não usar para esse fim? (uma vez que são mais de 40 anos de uso e aumento de demanda, sem ampliação).

Mas se mesmo assim afirmarem que não há a necessidade de ampliar a edificação em si o quê é pouco provável - questionamos então mais fortemente: porque danificar uma área pronta para ser transformada numa praça em ... estacionamento!?

Além disso, qual a razão para cercar a praça? Proteger o precário mobiliário urbano que ali existe? Ou impedir que pessoas ali frequentem?

Há pouco tempo, o centro de Presidente Prudente recebeu obras de requalificação no calçadão, principal rua para pedestres. De uma maneira geral, o resultado foi muito positivo, renovando pouco a pouco o espírito das pessoas de irem passear ao centro, reerguendo a auto estima dos locais e reduzindo a sensação de medo que pairam no ar nos velhos centros urbanos.

Será que não seria mais interessante buscar outra solução para ampliação do estacionamento, como o lote em desuso (ao lado do Poupatempo- pertencente ao Estado de São Paulo) deixando a área verde e reestruturando a praça toda?

Diante destas indagações, os alunos de arquitetura e urbanismo fizeram uma intervenção urbana chamada "A Praça é Nossa", a fim de alertar um problema e fazer a denúncia pública do que está ocorrendo. Ocorreu no dia vinte e um de novembro de dois mil e doze as nove da manhã. 
Abordou-se especificamente as ações de redução da praça, e o fechamento da mesma para um novo estacionamento da rodoviária, e a interrupção do fluxo de pedestres, privatização de um espaço que poderia ser público (estacionamento) e não solução para os problemas reais.

A Intervenção (figuras 6 e 7) foi realizada com painéis ilustrando atividades em praça, cartazes com frases de impacto, e um piquenique ilustrando uma apropriação do espaço urbano. Ao conversar com os usuários, constatou-se a insegurança que sentem ali e ao mesmo tempo, muitos lamentaram a perda de área verde.

A justificativa municipal para a instalação de grades na praça, é a insegurança, que acaba sendo o ponto de encontro da marginalização, ocorrendo furtos e outros tipos de violência urbana.

O movimento pós-modernista defendeu o resgate da cidade pelas pessoas, tendo como precursora Jane Jacobs (1960, p.35) cuja crítica questionava o modelo de cidade moderna segregacionista. Ele descreve algumas características para obter espaços públicos seguros:

Primeira, deve ser nítida a separação entre o espaço público e o espaço privado. O espaço público e privado não podem mistura-se, como normalmente ocorre me subúrbios ou em conjuntos habitacionais. Segunda, devem existir olhos para a rua, os olhos daqueles que podemos chamar de proprietários naturais da rua. Os edifícios de uma rua preparada para receber estranhos e garantir a segurança tanto deles quanto dos moradores devem estar voltados para a rua. Eles não podem estar com os fundos ou um lado morto para a rua e deixa-la cega. E terceira, a calçada deve ter usuários transitando initerruptamente, tanto pata aumentar na rua o número de olhos atentos quanto para induzir um numero suficiente de pessoas dentro dos edifícios da rua a observar as calçadas.

Para que isso aconteça de forma natural, faz-se necessário fomentar um ambiente urbano propício onde à segurança seja dada pela própria presença dos usuários nos espaços públicos. Esta área do terminal, junto com os outros equipamentos tem um grande potencial de atrair pessoas, gerando um movimento constante e oferecendo um local de espera ao ar livre aos passageiros.

Para melhorar a segurança, é de suma importância ter uma infraestrutura adequada, com mobiliário urbano, iluminação, paisagismo que convide e estimule o uso livremente dos espaços públicos, de forma que as atitudes não sejam regidas pela política do medo ou da punição.

O fechamento da Praça dos Pioneiros com grades não trouxe uma solução condizente aos problemas de marginalização e violência urbana, que continuam na área, e quando reprimidos se locomovem para outro lugar da cidade. 
Andarilhos e pessoas em situação de rua são reflexos de nossa organização social, valendo tirar como exemplo projetos bem sucedidos como o "Tecendo São Paulo" que apresentam uma proposta mais humana e que atende as reais demandas desta parcela da população.

Estamos assistindo cada vez mais, um grande movimento de privatização dos espaços públicos seja no trabalho (escritórios fechados com recepção e segurança), locais de estudo (escolas e faculdades fechadas), moradias (condomínios residenciais fechados), lazer (shoppings centers), todos regidos pela tese da cidade insegura; manipulando de tal forma a população que cada vez mais recorrem aos "casulos" blindados, câmeras e seguranças.

A segregação, espacial ou social, alimenta o sistema que pertencemos, e segundo BÓGUS (2005) está longe de ser uma alternativa para a insegurança de nossas cidades:

A privatização de espaços públicos não é solução, nem mesmo paliativa, para a falta de segurança. Para a elite que habita as cidades com carros blindados e circula entre os espaços fortificados de residência, trabalho, estudo e lazer, a cidade vem perdendo suas características fundamentais de urbe, espaço de convivência e de exercício da cidadania. Passa a ser apenas lugar da circulação, da passagem, do ir e vir. Até a população de menor renda começa a buscar proteção em conjuntos residenciais murados, reproduzindo, com a ajuda dos promotores imobiliários, soluções adotadas nos bairros mais valorizados. Possuem menos infraestrutura e serviços, mas buscam a sensação de segurança. A segregação surge como consequência quase inevitável do processo de privatização dos espaços públicos e do confinamento sócioespacial. Uma resposta extremamente insatisfatória para o quadro de insegurança, cujo real enfrentamento depende da atuação conjunta do Estado e da sociedade civil.

O fechamento da praça com gradil, não só afeta todas as oportunidade que este espaço urbano poderia oferecer aos que ali frequentam, como também a cidade de Presidente Prudente como um todo.

Além disso, organizar o trânsito dando prioridade aos pedestres, ciclistas, transporte coletivo e então o individual é mais do que conceito básico de urbanidade e cidadania. Oferecer áreas verdes abertas e com qualidade (com constante manutenção nas plantas e mobiliário urbano) é criar oportunidade para gerar encontros gratuitos, ao ar livre e consequência melhora a qualidade de vida. 


\section{CONCLUSÃO}

A partir de estudos realizados foi concluído que a região do terminal rodoviário é de sua importância para a cidade pois apresenta vários equipamentos público considerados polo gerador de pessoas, mercadorias, serviços, atividades.

Para melhor execução de sua função, faz se necessário melhorar a qualidade ambiental desta região, através um projeto urbano que vá de encontro a suas reais necessidades, abrangendo aspectos físicos e sociais.

Porém com a intervenção feita no ano passado, expansão do estacionamento para o lote lateral, impermeabilizou-se uma que poderia ser transformada em praça e rompeu o fluxo de pedestres, fechamento da praça com gradil. Acreditamos que esta intervenção intensificou a não relação de todos os equipamentos presentes nessa área, interrompendo fluxos, e perdendo a oportunidade de melhorar a qualidade urbana desta área.

\section{AGRADECIMENTOS}

Agradeço primeiramente a Deus, minha família ao Paulo Fernando Jurado pela força e paciência a orientadora Karin Fernanda Schwambach pelo estimulo e a todos de alguma forma que contribuíram para o resultado da pesquisa e do projeto de intervenção urbana realizada em 2012 pelos alunos da disciplina de Urbanismo IV do Sexto Termo de Arquitetura e Urbanismo da Universidade do Oeste Paulista.

\section{REFERÊNCIAS}

BÓGUS, Lucia. Privatização de espaços públicos: solução ou segregação?. Seção Fato e Opinião. Opinião concedida a Candido Malta. Revista AU Arquitetura e Urbanismo. Piniweb, edição 135, jul. 2005. Disponível em: <http://www.revistaau.com.br/arquitetura-urbanismo/135/privatizacao-deespacos-publicos-solucao-ou-segregacao-22732-1.asp>. Acesso em: 11 ago. 2013.

JACOBS, Jane. Morte e vida das grande cidades. São Paulo: Martins Fontes, 2007.

LYNCH, Kevin. A imagem da cidade. São Paulo: Martins Fontes, 2006.

TECENDO SÃO PAULO. Minha Rua Minha Casa. Canal Tecendo São Paulo. Youtube. 2012.

Disponível em: <http://www.youtube.com/watch?v=o38WGHK7rnc>. Acesso em: 11 ago. 2013. 